\title{
Earthquake exposes gaps in seismic network
}

Tokyo. The devastating earthquake and tsunami that struck the coast of northern Japan last week, killing more than 200 people, has drawn attention to gaps and duplication in Japan's seismic networks used for earthquake prediction and disaster prevention.

Last week's was the second major earthquake in the Japan Sea in recent years; on 26 May 1983, another struck a few hundred kilometres further south and killed 104 people, again largely because of the accompanying tsunami. Both earthquakes occurred in a major fault zone which has nevertheless not been designated as one for special monitoring and protection under Japan's earthquake countermeasures law.

The earthquake, measuring 7.8 on the Richter scale, struck in the middle of the night just north of the little island of Okushiri, off the northern island of Hokkaido. Most of the 4,700 inhabitants quickly realized the threat from tsunami - several of the island's houses were washed away by tsunami from the more distant 1983 earthquake and so fled to higher ground.

Others were not so lucky. The shorefront Yoyoso Hotel on Okushiri was struck from behind by a landslide and then from the front by a series of tsunami, the first about five minutes after the earthquake. The tsunami reached a maximum of 30 metres above sea level in the southwest part of the island, according to preliminary measurements by scientists from Tokyo and Tohoku Universities. That would make the tsunami the highest to have hit Japan since a 38-metre tsunami killed 22,000 in the Sanriku region in 1896.

The town of Aonae on the island's southern tip was devastated last week. Half of its 700 houses were destroyed by an uncontrollable fire caused by a ruptured propane tank.

Tsunami also caused extensive damage on the east coast of Russia and Korea, but there seem to have been few casualties.

There have been six major earthquakes since 1940 in the seismically active fault zone, which runs parallel to the west coast of Japan. The poor understanding of the region is attributable to a lack of seismograph stations, according to Hideki Shimamura, of Hokkaido University's laboratory for ocean bottom seismology.

Along the Pacific coast and within about $200 \mathrm{~km}$ of Tokyo, there are 133 observation instruments, including 54 land-based seismographs and 8 ocean bottom seismographs run by various government organizations, but that there are only 9 seismograph stations along the $400-\mathrm{km}$ Japan Sea coast of Hokkaido.

This week, Shimamura hopes to deploy 10-15 ocean bottom seismographs in the region around the earthquake's epicentre, using a Japan Meteorological Agency ship for the purpose. Temporary seismographs have also been set up on Okushiri. But more permanent stations are clearly needed in the region.

Under Japan's Large-scale Earthquake Countermeasures Act, ten regions have been designated for intense observation, but the list has not been revised since 1978 and the

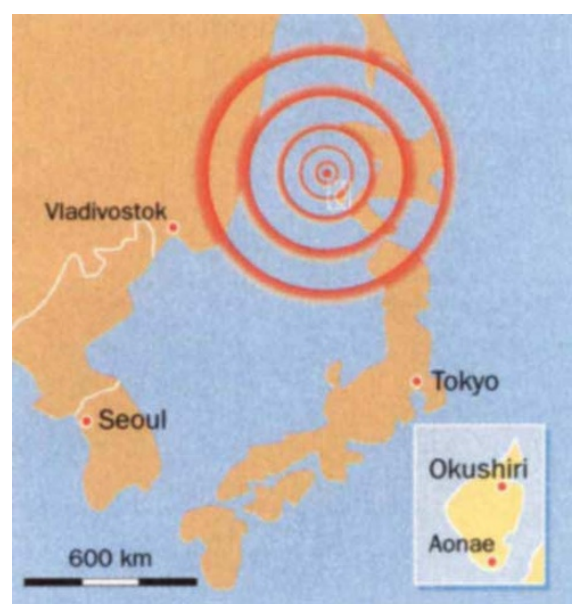

active fault-zone in the Japan Sea is not among them.

Kiyoo Mogi, chairman of the coordinat- ing committee for earthquake prediction, announced last week that the committee would consider designating the region as one for more intense observation in its next five-year plan, due to be published later this month. But designation is highly political because it can depress land prices and drive up the cost of insurance. Equally, it is difficult to remove regions already designated because that would mean loss of government subsidies for protection against tsunami and earthquakes.

In any case, designation does not necessarily result in an efficient network. In the Kanto and Tokai regions around Tokyo, six different government ministries and agencies conduct seismological, geodetic and geological observations, sometimes from separate stations barely 50 metres apart. Government bureaucracy limits the exchange of data between different government agencies and data are not made quickly and freely available to researchers outside the prediction programme. Despite complaints by Earth scientists outside the prediction programme, the now-elderly scientists who set it up seem determined to keep it on its 30 year-old course.

David Swinbanks

\section{No major changes in earthquake prediction}

Tokyo. Despite severe criticism, Japan's earthquake prediction programme seems unlikely to be shaken up by last week's earthquake in the Japan Sea.

The programme was formally reviewed last year, at the end of its sixth five-year phase, when outside opinions were sought for the first time. Several researchers criticized the programmes's objectives and organization; it has consumed about a billion dollars and engaged about 500 researchers over the past 20 of its 30 years (see Nature 356, 464; 1992).

The external review was never made public, but some who attended the hearings

in May last year say that some of the reviewers, who included Saburo Nagakura, president of the Graduate University of Advanced Studies, were very critical and even questioned the premise that earthquake prediction is possible.

But those who have seen the plan for the next five years say that "only cosmetic changes in wording" have been made, placing more emphasis on "basic research". They also say there is no fundamental change in the direction of the programme, which concentrates on collecting empirical data in the belief that one day a reliable precursor of earthquakes will be found.

The committee has some things to say in its own defence. Kiyoo Mogi, chairman of the earthquake prediction committee, suggested last year that a new type of "grey" prediction should be introduced, allowing the committee to say that an earthquake "might" occur. But that idea has been rejected by government bureaucrats, who have written laws specifying that the committee must give black or white decisions.

Aona engulfed in flames - with ships washed up by tsunami.

David Swinbanks 